University of Nebraska - Lincoln

DigitalCommons@University of Nebraska - Lincoln

U.S. Navy Research

U.S. Department of Defense

2002

\title{
Chloroquine-resistant Plasmodium malariae in south Sumatra, Indonesia
}

Jason D. Maguire

U.S. Naval Medical Research Unit \# 2, maguirejd@namru2.med.navy.mil

Iwa W. Sumawinata

U.S. Naval Medical Research Unit \# 2

Sofyan Masbar

U.S. Naval Medical Research Unit \# 2

Budhi Laksana

U.S. Naval Medical Research Unit \# 2

Purnomo Prodjodipuro

U.S. Naval Medical Research Unit \# 2

See next page for additional authors

Follow this and additional works at: https://digitalcommons.unl.edu/usnavyresearch

Maguire, Jason D.; Sumawinata, Iwa W.; Masbar, Sofyan; Laksana, Budhi; Prodjodipuro, Purnomo; Susanti, Ika; Sismadi, Priyanto; Mahmud, Nurlis; Bangs, Michael J.; and Baird, J. Kevin, "Chloroquine-resistant Plasmodium malariae in south Sumatra, Indonesia" (2002). U.S. Navy Research. 89.

https://digitalcommons.unl.edu/usnavyresearch/89

This Article is brought to you for free and open access by the U.S. Department of Defense at DigitalCommons@University of Nebraska - Lincoln. It has been accepted for inclusion in U.S. Navy Research by an authorized administrator of DigitalCommons@University of Nebraska - Lincoln. 


\section{Authors}

Jason D. Maguire, Iwa W. Sumawinata, Sofyan Masbar, Budhi Laksana, Purnomo Prodjodipuro, Ika Susanti, Priyanto Sismadi, Nurlis Mahmud, Michael J. Bangs, and J. Kevin Baird 


\title{
Chloroquine-resistant Plasmodium malariae in south Sumatra, Indonesia
}

\author{
Jason D Maguire, Iwa W Sumawinata, Sofyan Masbar, \\ Budhi Laksana, Purnomo Prodjodipuro, Ika Susanti, \\ Priyanto Sismadi, Nurlis Mahmud, Michael J Bangs, \\ $J$ Kevin Baird
}

Oral chloroquine is the treatment of choice for uncomplicated Plasmodium malariae infections worldwide. We did a prospective 28-day in-vivo assessment of the efficacy of chloroquine for treatment of $\boldsymbol{P}$ malariae on Legundi Island in Lampung Bay, Sumatra, Indonesia. Of 28 patients, one had recurrent parasitaemia on day 28 , and two had persistent parasitaemia to day 8 . Whole-blood chloroquine and desethylchloroquine concentrations were at ordinarily effective levels $(\geqslant 100 \mu \mathrm{g} / \mathrm{L})$ on day 8 in both cases of persistent parasitaemia. These findings suggest that clinical resistance to chloroquine by $P$ malariae occurs in the Indonesian archipelago of southeast Asia.

Lancet 2002; 360: 58-60

Plasmodium malariae causes quartan malaria - an important re-emerging parasitic disease around the globe. Although well described in eastern Indonesia and common in Java and Sumatra during the early 20th century, we have found no recent record of $P$ malariae in the western Indonesian archipelago. Oral chloroquine remains the treatment of choice for uncomplicated quartan malaria, and although chloroquine therapy for Plasmodium falciparum and Plasmodium vivax infections in Indonesia often fails, $P$ malariae is presumed sensitive to chloroquine, and resistance has not been documented.

In August, 2000, we identified a focus of $P$ malariae on the island of Legundi in Lampung Bay near the southernmost tip of Sumatra at the Sunda Strait. Since chloroquine use is heavy in this area, we aimed to find out whether chloroquine resistance could develop in $P$ malariae. Infected individuals were identified by a crosssectional prevalence survey for malaria, and were enrolled in a 28-day in-vivo test of resistance to chloroquine. Patients were treated with the standard chloroquine regimen, in accordance with a protocol approved by the United States Naval Medical Research Unit Institutional 

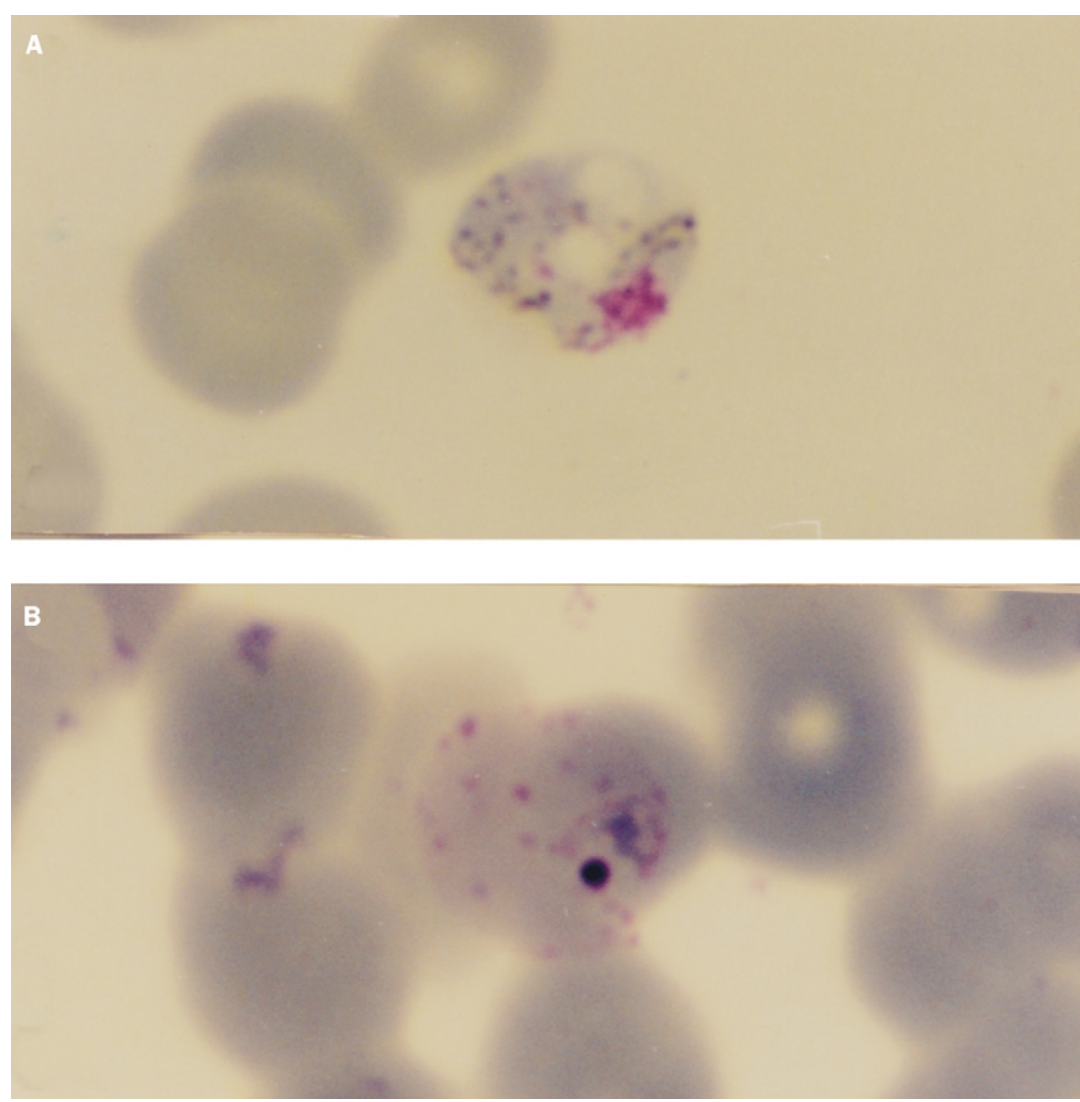

Figure 1: Giemsa-stained peripheral blood in patients with Plasmodium malariae infection

A: Day-7 sample from patient with persistent $P$ malariae parasitaemia. On day 8 , this patient's whole-blood chloroquine and desethylchloroquine concentration was $170 \mu \mathrm{g} / \mathrm{L}$ and was positive for $P$ malariae and $P$ falciparum. Note characteristic course, scattered, golden pigment and vacuolated late trophozoite form in normal-sized red blood cell. B: Day-8 sample from patient whose whole-blood chloroquine and desethylchloroquine concentration was $100 \mu \mathrm{g} / \mathrm{L}$ and was positive for $P$ malariae and negative for $P$ falciparum. Note ring stage in normal-sized red blood cell with prominent Ziemann's stippling.

Review Board and the ethical review committee of the host country. All patients provided informed consent. Patients received directly observed doses of chloroquine diphosphate (Resochin, P T Bayer Indonesia, Jakarta): $10 \mathrm{mg}$ base $/ \mathrm{kg}$ on day $0,10 \mathrm{mg}$ base $/ \mathrm{kg}$ on day 1 , and $5 \mathrm{mg}$ base/kg on day 2 , and were followed up for 28 days.

Malaria smears were prepared on days $0,1,2,3,4,7$, $11,14,18,21,28$, or any day a patient complained of illness. Blood-blot specimens were obtained for measurement of whole-blood chloroquine concentrations by high-performance liquid chromatography (Model 2700, Bio-Rad, Richmond, CA, USA) on day 0 (pretreatment), day 2, day 28 , or the day of recurrent parasitaemia. Bloodblot specimens were also obtained for plasmodial DNA analysis on days $0,7,14,21,28$, or the day of recurrent parasitaemia. Patients with persistent or recurrent parasitaemia during follow-up were treated with pyrimethamine-sulfadoxine according to Indonesian Ministry of Health guidelines. Studies done elsewhere show that, after standard chloroquine therapy, $P$ malariae parasitaemia clears within $24-72 \mathrm{~h}$ and does not recur. ${ }^{1,2}$ We therefore considered $P$ malariae parasitaemia persisting beyond $72 \mathrm{~h}$ as evidence of an inadequate therapeutic response consistent with chloroquine resistance.

Active screening of $41 \%(752 / 1819)$ of the population revealed an overall $17 \%(127 / 752)$ prevalence of parasitaemia by plasmodia $(31.5 \%$ $P$ falciparum, $30 \%$ P vivax, $37 \%$ $P$ malariae, $1.5 \%$ both $P$ falciparum and $P$ vivax). At the two primary villages of Selesung and Keramat, prevalence was $15 \% \quad(59 / 408)$ and $23 \% \quad(56 / 247)$, respectively. $P$ malariae was the most common species at both locations, accounting for $41 \%(24 / 59)$ in Selesung and $39 \%(22 / 56)$ of positive smears in Keramat. Spleen rates and average enlarged spleen (AES) indices among children (2-9 years) were $68 \%(59 / 87$; AES $1 \cdot 8)$ in Selesung and $81 \%(43 / 53$; AES 2.7) in Keramat.

Among 47 patients with $P$ malariae infection in the prevalence survey, we enrolled 28 in the test of resistance to chloroquine. 15 were male and 13 were female, and ages ranged from 6 to 65 years (mean 13). Four patients had mixed $P$ malariae and $P$ vivax infections. One declined further participation after day 2, which left 27 individuals who successfully completed the test. The mean asexual parasite count was $220 / \mu \mathrm{L}$ (range 40-1120) at baseline. Only one patient had detectable $P$ malariae gametocytes. The blood of 18 individuals had evidence of chloroquine and its major metabolite desethylchloroquine before treatment (mean concentration $142.5 \mu \mathrm{g} / \mathrm{L}$ [SD 116.5]), which suggested that island residents practised routine self-administration of chloroquine.

All but two of the 28 enrolled patients cleared $P$ malariae parasitaemia after treatment. The mean time to asexualstage parasite clearance in 24 of 26 individuals who initially cleared parasitaemia, irrespective of eventual outcome, was 2 days (range 1-4). The times to clearance could not be determined in the other two patients. In both cases, parasitaemia was still present on day 4 , but the patients did not undergo another malaria smear until day 7 in 1 case and day 13 in the other, at which time malaria smears were negative for parasites.

18 of the 27 individuals who completed the test remained parasite-free on day 28. During follow-up, six patients developed asexual-stage parasitaemia with a species other than $P$ malariae: three with $P$ falciparum on day 18 , one with $P$ vivax on day 21 , and two with $P$ vivax on day 28. These cases represented intercurrent infections with a different species or possibly relapse in cases of $P$ vivax infection.

Of the three remaining patients, two had persistent $P$ malariae parasitaemia to day 8 , and one had recurrent parasitaemia on day 28 . The 28 -day cumulative incidence of therapeutic failure was $12 \%$ by life-table (actuarial) analysis. Thick-smear asexual parasite counts (per $\mu \mathrm{L}$ ) for the two patients with persistent parasitaemia on days 0,1 , $2,3,4,7$, and 8 were 520,120 , not done, not done, 80,80 , 40 ; and $520,240,40,80,80,80,80$, respectively. In the same two individuals, day 2 chloroquine and desethylchloroquine concentrations were $205 \mu \mathrm{g} / \mathrm{L}$ and $680 \mu \mathrm{g} / \mathrm{L}$, respectively. Just before rescue therapy with pyrimethamine-sulfadoxine on day 8 , their chloroquine and desethylchloroquine concentrations were $100 \mu \mathrm{g} / \mathrm{L}$ and 

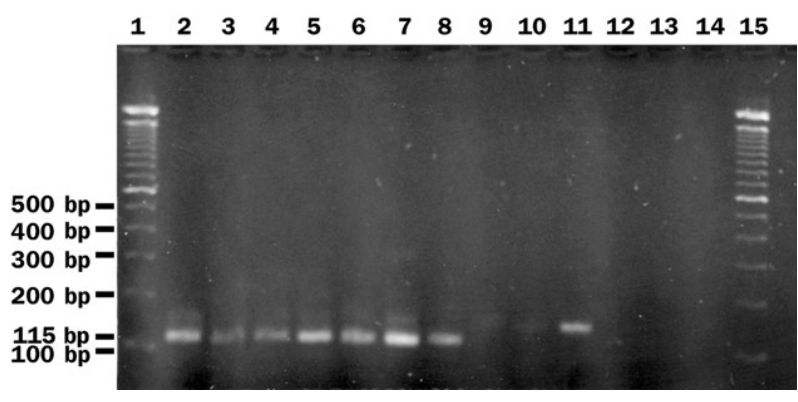

Figure 2: Electrophoresis after Plasmodium-malariae-specific PCR amplification

Lanes 1 and 15: bp ladder; lane 2: patient LG004 day 0; lane 3: patient LG004 day 28; lane 4: patient LG033 day 0; lane 5: patient LG033 day 8; lane 6: patient LG046 day 0; lane 7: patient LG046 day 8; lane 8: $P$ malariae positive control; lane 9: $P$ falciparum control; lane 10: $P$ vivax control; lane 11: $P$ ovale control; lanes 12,13 , and 14 : negative controls.

$170 \mu \mathrm{g} / \mathrm{L}$. The patient with recurrent $P$ malariae parasitaemia on day 28 cleared parasitaemia 1 day after initiation of therapy and had a chloroquine and desethylchloroquine concentration of $450 \mu \mathrm{g} / \mathrm{L}$ on day 2, which we deemed consistent with adequate absorption of drug. The chloroquine and desethylchloroquine concentration on the day of recurrence was $35 \mu \mathrm{g} / \mathrm{L}$.

Diagnoses were established by standard light microscopy and PCR. The microscopic diagnosis of $P$ malariae was based on the presence of characteristic pigmented band forms and scattered, course pigment granules in prominently vacuolated late trophozoites in normal-sized red blood cells (figure 1). Diagnoses of recurrent or persistent $P$ malariae infection were confirmed by speciesspecific single-stranded ribosomal RNA PCR methods. ${ }^{3}$ In all three cases of therapeutic failure, blood-blot specimens obtained on day 0 and the day of rescue therapy were positive for $P$ malariae by PCR (figure 2 ). Neither $P$ vivax nor $P$ ovale were detected in these specimens. One of the patients with persistent $P$ malariae parasitaemia on day 8 was also PCR-positive for $P$ falciparum on day 0 and day 8 . We believe that this individual might have had a mixed infection with subpatent $P$ falciparum parasitaemia. $P$ malariae can suppress parasitaemia of subsequent $P$ falciparum superinfections. ${ }^{4}$

The case of recurrent $P$ malariae parasitaemia on day 28 could represent either new infection or late recrudescence of a chloroquine-resistant strain, but the two cases of $P$ malariae persisting for 8 days after directly observed chloroquine therapy with adequate absorption constitute evidence of resistance. The time to parasite clearance seen in this study and others ${ }^{1,2}$ supports our view that these two cases represent treatment failures due to inadequate therapeutic response by the parasite, rather than delayed clearance. Although $P$ malariae has a longer cycle of schizogony than other human plasmodia, we have seen no evidence to suggest that chloroquine-sensitive $P$ malariae survives beyond $72 \mathrm{~h}$ after the patient starts standard chloroquine treatment. Figure 1 shows that these patients still carried developing late trophozoites 7 days after initiation of chloroquine therapy. In previous reports of natural infection, ${ }^{2}$ time to parasite clearance did not exceed 2 days. Collins and colleagues $^{1}$ reported 13 chloroquine-treated experimental $P$ malariae infections with parasite clearance times ranging from 1 to 7 days. However, these were experimental infections, many of which were manipulated by low-dose quinine sulphate for several months before definitive treatment with chloroquine, and in most cases, patients received only a single dose of $600 \mathrm{mg}$ chloroquine base rather than a standard 3-day regimen. Those parasite clearance times cannot therefore be compared with those in naturally infected patients treated with the standard 3-day course of chloroquine. The presence of early ring-form parasites as late as day 8 (figure 1) also suggests ongoing schizogony. The persistence of healthy asexual-stage parasitaemia to day 8 after adequate chloroquine absorption and in the presence of ordinarily effective chloroquine and desethylchloroquine concentrations ${ }^{5}$ is highly suggestive of resistance to chloroquine by $P$ malariae.

Health-care providers could encounter patients with uncomplicated $P$ malariae infection that proves unresponsive to the recommended chloroquine regimen. Further assessment of chloroquine-resistant $P$ malariae at other locations around the world is needed, particularly in areas where indiscriminate chloroquine use is common and could lead to inadequate dosing and selection for resistant organisms.

Contributors

J Maguire was the principal investigator, project coordinator, and main author, and contributed to data interpretation; I W Sumawinata was a team field physician; S Masbar was a microscopist and field logistical coordinator; B Laksana was the high-performance liquid chromatography technologist and laboratory supervisor; P Prodjodipuro was the senior expert microscopist; A I Susanti was the principal PCR technologist; P Sismadi was the Indonesian Ministry of Health coordinator and a team field physician; $\mathrm{N}$ Mahmud was the district health office project coordinator; M J Bangs was the team field supervisor; and K Baird coordinated the implementation of the technology at NAMRU-2 and contributed to data interpretation.

Conflict of interest statement

None declared.

\section{Acknowledgments}

We thank the members of the NAMRU-2 Parasitic Diseases Program Clinical Trials Team for technical assistance, especially Krisin, Mark Lacy, Mochamad Awalludin Sutamihardja, Suradi, Sunardi, Bimo Wicaksana, and Dwiko Susapto. We also acknowledge the support of the Legundi Island health-worker team: Dicky Soehardiman, Sri Nurhayadi, Pinnur, Wayan Warso, Edi Trimulyono, Fahruji, Gofir, Mamun, Amrulloh, and M Taher.

This work was supported by the Republic of Indonesia Ministry of Health and Social Welfare, especially Ingerani and D Djamal. This research was funded by the US Department of Defense Global Emerging Infections Surveillance (GEIS) Program. The assertions herein are the views of the authors and do not reflect official policy of the US Department of the Navy, the US Department of Defense, or the US government.

1 Collins WE, Contacos PG, Chin W. Experimental infection in man with Plasmodium malariae. Am f Trop Med Hyg 1973; 22: 685-92.

2 Tan-ariya P, Pasuralertsakul S. First report if in vitro susceptibility of Plasmodium malariae Thai isolates to chloroquine. Southeast Asian $\mathcal{F}$ Trop Med Public Health 1994; 25: 784-87.

3 Kimura M, Kaneko O, Liu Q, et al. Identification of the four species of human malaria parasites by nested PCR that targets variant sequences in the small subunit rRNA gene. Parasitol Int 1997; 46: 91-95.

4 Mason DP, McKenzie FE, Bossert WH. The blood-stage dynamics of mixed Plasmodium malariae-Plasmodium falciparum infections. f Theor Biol 1999; 198: 549-66.

5 Rombo L, Bjorkman A, Sego E, Ericsson O. Whole blood concentrations of chloroquine and desethylchloroquine during and after treatment of adult patients infected with Plasmodium vivax, Povale, or P malariae. Trans R Soc Trop Med Hyg 1986; 80: 763-66.

United States Naval Medical Research Unit \#2, Jakarta, Indonesia (J D Maguire MD, I W Sumawinata MD, S Masbar BSc, B Laksana MSc, P Prodjodipuro MSc, M J Bangs PhD, J K Baird PhD); Indonesian Ministry of Health Institute of Health Research and Development, Jakarta (P Sismadi MD); and District Health Service, Kalianda, Lampung Selatan, Sumatra (N Mahmud PhD)

Correspondence to: Dr Jason D Maguire, US Embassy Jakarta, Unit 8132, NAMRU-TWO, FPO AP 96520-8132, Indonesia (e-mail: maguirejd@namru2.med.navy.mil) 